\title{
Pembuatan Bahan Bakar Diesel dari Limbah Plastik HDPE dengan Proses Pirolisis
}

\author{
(Production of Diesel Fuel from HDPE Plastic Waste by Pyrolysis Process) \\ Taufik Iskandar ${ }^{1}$, Sinar Perbawani Abrina Anggraini ${ }^{2}$, Melinda $^{3}$ \\ ${ }^{1}$ Pogram Studi Teknik Kimia, Fakultas Teknik, Universitas Tribhuwana Tunggadewi - Malang
}

\section{ARTICLE INFO}

Article history

Received : 03 February 2021

Revised : 10 Maret 2021

Accepted : 12 Maret 2021

\section{DOI :}

https://doi.org/10.33366/rekabua na.v6i1.2251

Keywords :

diesel fuel; HDPE; pyrolisis

e-mail corresponding author : taufik.iskandar@unitri.ac.id

\section{PENERBIT}

\section{UNITRI PRESS}

J1. Telagawarna, TlogomasMalang, 65144, Telp/Fax: $0341-565500$

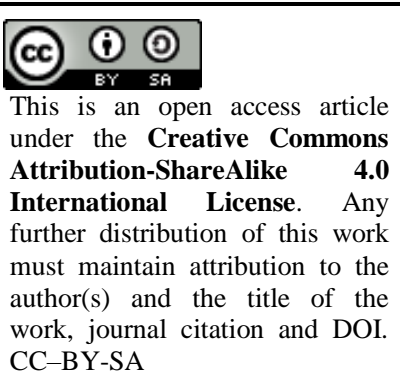

\section{ABSTRAK}

Indonesia menduduki posisi ke dua setelah cina penghasil sampah plastik terbesar di dunia. Dimana salah satu limbah plastik tersebut adalah HDPE (High Density Polyethylene). Sedangkan plastik merupakan produk hasil pengolahan minyak bumi yang dapat direcycle ke bentuk semulanya karena bahan baku pembuatan limbah plastik adalah nafta yang merupakan salah satu unsur dari minyak bumi. Salah satu solusi yang diperlukan adalah recycle dengan mengubah limbah plastik menjadi bahan bakar dengan proses pirolisis. Pirolisis merupakan salah satu proses terbaik dari recycle limbah plastik, dengan pertimbangan memahami sifat limbah plastik HDPE. Penelitian ini menggunakan alat pirolisis dengan variable suhu proses yaitu $300^{\circ} \mathrm{C}, 325^{\circ} \mathrm{C}$, dan $350^{\circ} \mathrm{C}$, waktu proses pirolisis yaitu 2 dan 4 jam. Dari proses pirolisis diperoleh hasil volume bahan bakar diesel yaitu pada suhu $300^{\circ} \mathrm{C}$ sebanyak $95 \mathrm{ml}$, suhu $325^{\circ} \mathrm{C}$ sebanyak $100 \mathrm{ml}$, dan suhu $350{ }^{\circ} \mathrm{C}$ sebanyak $145 \mathrm{ml}$. Dari hasil analisa data optimal untuk suhu dan waktu optimum proses pirolisis limbah plastik HDPE yaitu pada suhu $325^{\circ} \mathrm{C}$ selama 2 jam, bahan bakar diesel yang didapat memiliki kadar abu 0,044 (b/b), dan kadar air 0,031(\%vol).

\section{ABSTRACT}

Indonesia is in second place after China, the largest plastic waste producer in the world. Where one of the plastic wastes is HDPE (High-Density Polyethylene). Meanwhile, plastic is a product of petroleum processing that can be recycled to its original form because the raw material for making plastic waste is naphtha, which is an element of petroleum. One solution that is needed to recycle by converting plastic waste into fuel by the pyrolysis process. Pyrolysis is one of the best processes for recycling plastic waste, with consideration of understanding the nature of HDPE plastic waste. This study used a pyrolysis tool with process temperature variables, namely $300^{\circ} \mathrm{C}, 325^{\circ} \mathrm{C}$, and $350^{\circ} \mathrm{C}$, the pyrolysis process time was 2 and 4 hours. From the pyrolysis process, the results of the volume of diesel fuel are at a temperature of $300{ }^{\circ} \mathrm{C}$ as much as $95 \mathrm{ml}$, a temperature of $325 \mathrm{C}$ as much as $100 \mathrm{ml}$, and a temperature of $350 \circ \mathrm{C}$ as much as 145 $\mathrm{ml}$. From the results of the optimal data analysis for the optimum temperature and time of the HDPE plastic waste pyrolysis process, which is at a temperature of $325^{\circ} \mathrm{C}$ for 2 hours, the obtained diesel fuel has an ash content of 0.044 ( $w / w)$, and a moisture content of 0.031 (vol\%).

Cara Mengutip : Iskandar, T., Anggraini, S. P. A., Melinda, M. (2021). Pembuatan Bahan Bakar Diesel dari Limbah Plastik HDPE dengan Proses Pirolisis. Reka Buana : Jurnal Ilmiah Teknik Sipil dan Teknik Kimia, 6(1), 23-29. doi:https://doi.org/10.33366/rekabuana.v6i1.2251 


\section{PENDAHULUAN}

Sampah plastik HDPE merupakan salah satu pencemar lingkungan terbesar di Indonesia yang hingga saat ini masih minim solusinya [1]. Indonesia menduduki posisi ke dua setelah cina penghasil sampah plastik terbesar di dunia hal tersebut di perkuat oleh Pramiati Purwaningrum [2] yang menyatakan 14\% sampah yang dihasilkan manusia merupaakan plastik dan sisanya merupakan sampah organik dan sampah non organik. Peningkatan penggunaan plastik ini menyebabkan semakin meningkat juga limbahnya [3].

Minyak bumi merupakan salah satu kebutuhan energi manusia.Dari tahun ke tahun konsumsi minyak bumi semakin meningkat, tercatat Pada tahun 2019 kenaikan konsumsi minyak bumi meningkat sebesar $15 \%$ dari tahun 2018 [4]. Sehingga dikeluarkan kebijakan pemerintah Republik Indonesia No. 5 Tahun 2006 yang mengatur Kebijakan Energi di indonesia dimana Pemerintah telah menetapkan porsi penggunaan bahan bakar bumi pada tahun 2025 harus dapat dipangkas dari 52\% menjadi kurang dari $20 \%$.

Plastik HDPE (high dencity polyethylene) adalah polimer rantai panjang atom polietilen yang saling mengikat satu sama lain. Plastik HDPE merupakan material terbuat dari nafta yang merupakan produk turunan minyak bumi yang diperoleh melalui proses penyulingan [5]. Keunggulan plastik diantaranya adalah lebih kuat dan lebih flesibel tidak mudah pecah mudah diberi warna mudah dibentuk serta lebih tahan terhadap panas dan listrik.dari berbagai keunggulan tersebut meyebabkan plastik sulit diurai oleh lingkungan yang menyebabkan pencemaran tingkat tinggi terhadap tanah sehingga perlu dilakukan pengolahan yang tepat. Dimana sampah pastik yang terbuat dari minyak bumi dapat diolah kembali menjadi minyak bumi. HDPE (high density polyethylene) dalam kehidupan sehari-hari berupa kemaan obat, botol bayi, jerigen pelumas dan plastik kosmetik [6].

Plastik dapat dikelompokan menjadi dua jenis yaitu jenis thermoplastik dan jenis thermosetting. Thermoplastik adalah jenis plastik yang tergolong kedalam plastik yang dapa di daur ulang dengan proses pemanasan yang lebih sederhana, sedangkan thermosetting dalam pengolahanya memerlukan pemanasan yang lebih konflkex dan bahkan beberapa plastik jenis ini tidak bisa diolah dengan pemansan. Beerapa jenis plastik berdasarkan penyusunya yaitu Low Density Polyethylene (LDPE) High Density Polyethylene (HDPE), Polypropylene (PP), Polyethylene Terephthalate (PET), Polyvinyl Chloride (PVC), Polystyrene (PS) dan lainnya [7]. Komposisi sampah plastik pada umumnya yaitu 46\% Polyethylene berupa plastik LDPE dan HDPE, Polypropylene 16\% atau plastik PP, Polystyrene 16\% (PS), Polyvinyl Chloride 7\% (PVC), Polyethylene 5\% Trephthalate (PET), Acrylonitrile-Butadiene-Styrene 5\% (ABS) dan beberapa polimer lain. Sampah plastik yang mendominasi lebih dari $70 \%$ limbah adalah Polpropylene (PP), Polyethylene (PE), Polyvinyl Chloride (PVC), dan Polystyrene (PS) sehingga para peneliti cenderung melakukan penelitian dari limbah plastik jenis tersebut [3] [8]. 
Pirolisis adalah sebuah proses dekomposisi limbah plastik dengan memanfaatkan panas untuk memisahkan struktur penyusunya sehingga dapat menghasilkan produk yang diinginkan [9]. Berdasarkan beberapa pengamatan peneliti sebelumnya proses pirolisis sejauh ini merupakan proses terbaik dalam recycle limbah plastik.

Dalam tahap pengolahan pirolisis untuk menghasilkan produk yang diinginkan perlu memahami tentang sifat thermal dari plastik yang diolah. Dimana plastik HDPE yaitu titik lebur $330^{\circ} \mathrm{C}$, titik transisi $-115^{\circ} \mathrm{C}$, dan temperatur kerja maksimal sebesar $260{ }^{\circ} \mathrm{C}$. Terdapat beberapa hal yang berpengaruh terhadap kualitas dan kuantitas minyak yang dihasilkan. Faktor-faktor tersebut meliputi suhu, waktu, jenis plastik, dan penggunaan katalis dan jenis katalisnya [10]. Proses recycle ini dilakukan dengan memanfaatkan pemanasan terhadap limbah plastik. Pada prosesnya juga menghindari proses pembakaran langsung agar tidak menghasilan senyawa yang berbahaya bagi lingkungan, seperti polychlol dibenzodioxins dan policloro dibenzo-furans. Agar kandungan yang terdapat dalam plastik tidak berbahaya baagi lingkungan perlu dilakukan pemanasan dngan non udara [11]. Reaksi thermal plastik HDPE:

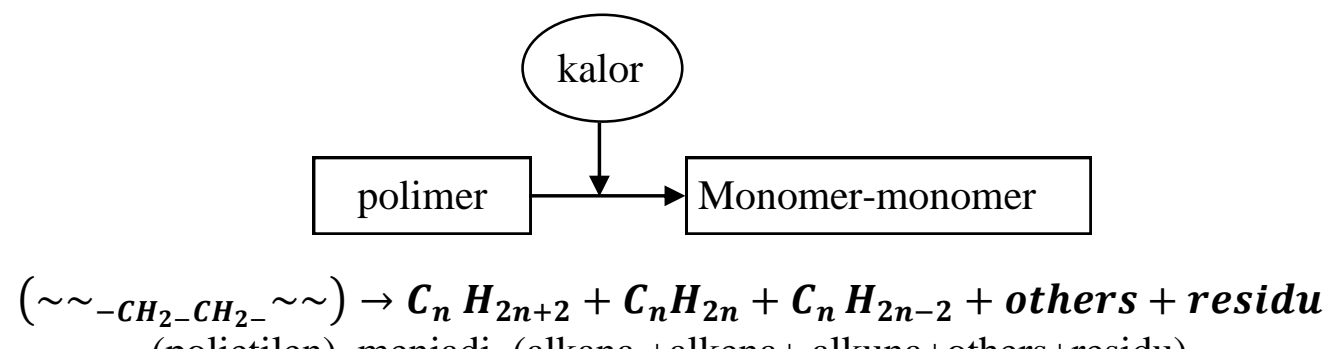

(polietilen) menjadi (alkana +alkena+ alkuna+others+residu)

\section{a. Bahan Bakar Diesel}

Bahan bakar diesel merupakan salah stu hasil minyak bumi yang dimanfaatkan untuk kebutuhan sehari-hari, dimana untuk menghasilkan minyak bumi dilakukan pengolahan minyak mentah dengan cara penyulingan dan lain sebagainya [7].

Bahan bakar diesel merupakan hasil proses penyulingan pada temperatur 200-340 ${ }^{\circ} \mathrm{C}$. sifat utama bahan bakar diesel yaitu, tidak mudah menguap, berbau menyengat, berwarna mirip seperti minyak tanah dan Mempunyai titik nyala tinggi $\left(40-100^{\circ} \mathrm{C}\right)$, akan terbakar pada suhu $350{ }^{\circ} \mathrm{C}$, berat jenis bahan bakar diesel yaitu 0,82-0,86, panas yang dihasilkan besar yaitu sekitar $10.500 \mathrm{kcal} / \mathrm{kg}$, kandungan sulfur dalam bahan bakar diesel lebih besar dari bensin, memiliki rantai hidrokarbon $\mathrm{C}_{14}-\mathrm{C}_{18}$.

Tabel 1. Standar mutu bahan bakar diesel

\begin{tabular}{lccc}
\hline \multicolumn{1}{c}{ Sifat } & \multicolumn{2}{c}{ Jenis minyak diesel } \\
\cline { 2 - 4 } & $\begin{array}{c}\text { Mesin putaran } \\
\text { tinggi }\end{array}$ & Mesin industri & $\begin{array}{c}\text { Mesin kapasitas } \\
\text { sedang kebawah }\end{array}$ \\
\hline Angka setane & $\geq 40$ & $\geq 40$ & $\geq 30$ \\
\hline Titik didih $\left({ }^{\circ} \mathrm{C}\right)$ & 288 & $282-338$ & - \\
\hline Viskositas $\left(\right.$ pada $\left.38 \mathrm{~mm}^{2} / \mathrm{s}\right)$ & $1.4-2.5$ & $2.0-4.3$ & $2.8-26.4$ \\
\hline Titik nyala $\left({ }^{\circ} \mathrm{C}\right)$ & $\geq 38$ & $\geq 52$ & $\geq 55$ \\
\hline Kadar sulfur $(\%$ berat) & $\geq 0.5$ & $\geq 0.5$ & $\geq 2.0$ \\
\hline Kadar air dan endapan $(\%$ volume $)$ & $\geq 0.05$ & $\geq 0.05$ & $\geq 0.5$ \\
\hline
\end{tabular}




\begin{tabular}{lllc}
\hline Kadar abu (\%berat) & $\geq 0.01$ & $\geq 0.01$ & $\geq 0.1$ \\
\hline $\begin{array}{l}\text { Ramsboton residu karbon dalam 10\% } \\
\text { residu destilasi (\% massa) }\end{array}$ & $\geq 0.15$ & $\geq 0.35$ & - \\
\hline
\end{tabular}

Karakteristik bahan bakar diesel meliputi: volatilitas, titik nyala, viskositas, kadar sulfur, kadar air, kadar abu, Kadar Residu Karbon, titk tuang, kadar karbon, kadar hidrogen, kadar setana, nilai kalor, massa jenis [6].

\section{b. Hal-hal yang mempengaruhi proses pembuatan bahan bakar diesel}

Kualitas dan kuantitas minyak bumi yang dihasilkan dipengaruhi oleh faktorfaktor antara lain suhu, waktu, jenis plastik, dan penggunaan katalis dan jenis katalisnya.

\section{c. Analisa hasil}

Analisa kadar air perlu dilakukan untuk mengetahui jumlah kandungan air dari bahan bakar dimana kandungan air sangan berdampak pada kualitas minyak, karena kandungan air didalamnya dapat mempengaruhi nilai kalor dan laju pembakaran. Untuk mengetahui kadar air dari suatu bahan bakar dapat dilakukan pengeringan dengan oven listrik. Analisa kadar abu juga merupakan salah satu analisa utama bahan bakar dimana analisa ini bertujuan untuk mengetahui berapa kadar abu yang terdapat di dalam bahan bakar sehingga dapat menentukan apakah bahan bakar tersebut memenuhi standar, Kadar abu merupakan kandungan yang dapat menyebabkan penyumbatan saat pemakaian bahan bakar.

\section{METODE PENELITIAN}

Proses pirolisis untuk pembuatan bahan bakar diesel dilakukan di laboratorium Bioenergi Program Studi Teknik Kimia, Fakultas Teknik, Universitas Tribhuwana Tunggadewi Malang. Variabel penelitian meliputi variabel tetap yang terdiri dari bahan baku limbah plastik HDPE dan berat bahan bakunya yaitu $1 \mathrm{~kg}$. Variabel berubah meliputi suhu pirolisis yaitu $300^{\circ} \mathrm{C}, 325^{\circ} \mathrm{C}, 350{ }^{\circ} \mathrm{C}$, dan waktu pirolisis selama 2 dan 4 jam. Alat penelitian yaitu alat pirolisis dan bahan penelitian yang digunakan yaitu limbah plastik HDPE.

\section{Prosedur penelitian}

Limbah plastik HDPE dilakukan pencucian, kemudian dikeringkan dengan dijemur, setelah itu dilakukan pencacahan, Limbah plastik yang telah dicacah. dimasukan ke dalam reaktor pirolisis dan suhu yang diaplikasikan yaitu 300, 325,350 $\left({ }^{\circ} \mathrm{C}\right)$.dengan waktu 2 dan 4 (jam). Kemudian uap hasil pembakaran masuk ke dalam kondensor untuk merubah fase gas ke cair sehingga diperoleh bahan bakar diesel.

\section{HASIL DAN PEMBAHASAN}

Adapun dari $1 \mathrm{~kg}$ limbah plastik setelah dikonversikan ke volume (ml) sama dengan $1145 \mathrm{ml}$ bahan bakar diesel. 
Tabel 2. Volume bahan bakar dan limbah yang dihasilkan

\begin{tabular}{ccccc}
\hline No & Suhu $\left({ }^{\circ} \mathbf{C}\right)$ & $\begin{array}{c}\text { Waktu } \\
(\mathbf{j a m})\end{array}$ & $\begin{array}{c}\text { Volume bahan bakar } \\
(\mathbf{m l} / \mathbf{k g})\end{array}$ & $\begin{array}{c}\text { Volume limbah } \\
\text { yang tidak } \\
\text { terkonversi }(\mathbf{m l} / \mathbf{k g})\end{array}$ \\
\cline { 1 - 4 } 1 & 300 & 2 & 40 & 1055 \\
\cline { 2 - 4 } 2 & 325 & 4 & 45 & 1035 \\
\cline { 2 - 4 } 3 & 350 & 4 & 40 & \multirow{2}{*}{895} \\
\cline { 2 - 4 } & & 4 & 105 & \\
\hline
\end{tabular}

Adapun pegecekan kualitas bahan bakar diesel dari variabel suhu dan waktu yng telah ditentukan sebagai berikut:

\section{a. Data Kadar Air}

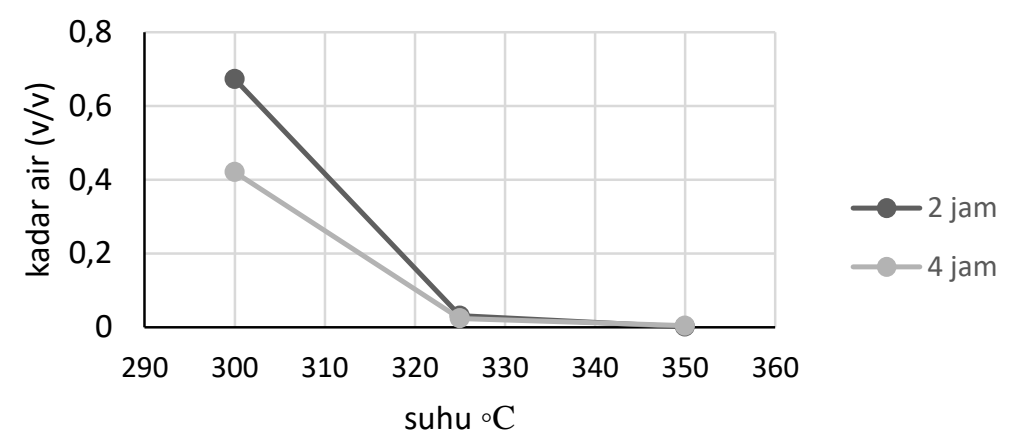

\section{Gambar 1. Grafik kadar air}

Berdasarkan gambar 1 diatas menunjukan semakin tinggi suhu pirlolisis dan semakin lama waktu pirolisis maka dalam bahan bakar kadar airnya akan semakin rendah karena semakin tinggi suhu dan waktu proses pirolisis, maka air yang akan menguap akan semakin tinggi, kadar air terendah, Pada suhu pirolisis $350{ }^{\circ} \mathrm{C}$ dan waktu pirolisis selama 4 jam mengasilkan kadar air sebesar 0,004(v/v) dimana hasil ini sudah memenuhi SNI yaitu sebesar $0,05(\mathrm{v} / \mathrm{v})$ sedangkan kadar air tertinggi yaitu pada suhu $300^{\circ} \mathrm{C}$ dengan waktu pirolisis 2 jam sebesar $0,672(\mathrm{v} / \mathrm{v})$.

\section{b. Kadar Abu Bahan Bakar Diesel}

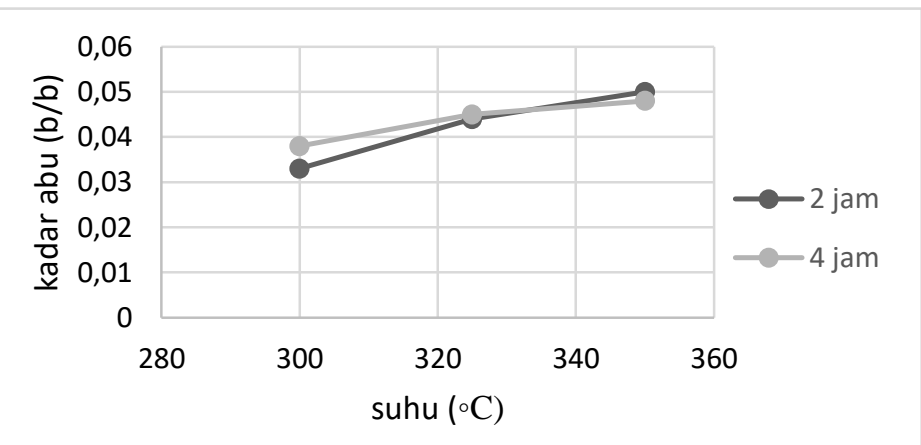

Gambar 2. Grafik kadar abu 
Berdasarkan gambar 2 diatas dapat disimpulkan bahwa suhu dan waktu pembakaran yang tepat diterapkan dalam proses pirolisis yaitu pada suhu yang rendah serta waktu pirolisis yang menghasilkan kadar abu terendah adalah waktu pirolisis yang lebih singkat hal ini karena suhu pembakaran yang terlalu tinggi dan waktu pembakaran yang lebih lama akan menyebabkan bahan bakar menerima panas yang tinggi dalam waktu yang lama sehingga mempengaruhi kadar abu yang dihasilkan dalam proses pembakaran yang menyebabkan kadar abu ikut terkondensasi ke dalam bahan bakar. Pada suhu $350^{\circ} \mathrm{C}$ dan 4 jam waktu yang diaplikasikan menghasilkan kadar abu sebesar 0,048 (b/b) dan kadar abu terendah yaitu pada suhu $300{ }^{\circ} \mathrm{C}$ dan waktu pirolisis selama 2 jam $0,162(\mathrm{~b} / \mathrm{b})$.

\section{c. Titik Optimal Dari Variabel Penelitian}

Untuk mengetahui suhu dan waktu optimal dari proses pirolisis limbah plastik HDPE diperlukan analisa hasil dari berbagai variabel proses terhadap analisa hasil menggunakan minitab sbb:

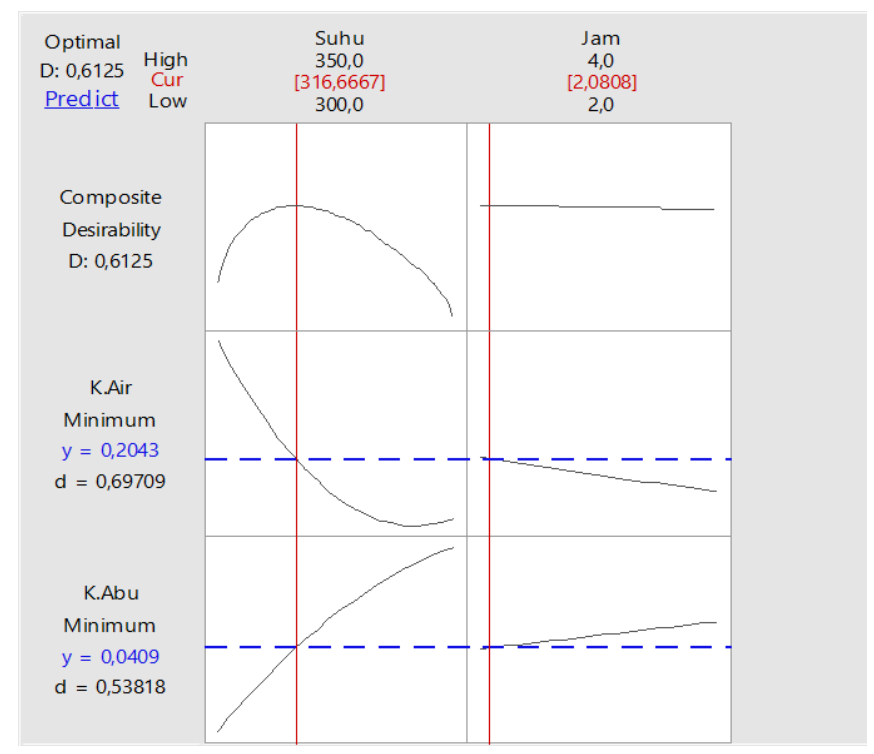

Gambar 3. Grafik nilai optimal

Setelah dianalisa SPSS dengan membandingkan hasil kadar air dan kadar abu diperoleh bahwa nilai optimal yang dihasilkan adalah pada suhu $325{ }^{\circ} \mathrm{C}$ selama 2 jam dengan nilai maksimum 0,044 (b/b), dan kadar air 0,031 (v/v).

\section{KESIMPULAN}

Dari hasil analisa data optimal untuk suhu dan waktu optimum proses pirolisis limbah plastik HDPE yaitu pada suhu $325{ }^{\circ} \mathrm{C}$ selama 2 jam. Dari suhu dan waktu terbaik proses pengolahan limbah plastik HDPE menjadi bahan bakar diesel yaitu pada suhu $325{ }^{\circ} \mathrm{C}$ selama 2 jam diperoleh kadar abu 0,044 (b/b), dan kadar air 0,031 (v/v). Dari analisa titik optimal proses pirolisis limbah plastik HDPE, suhu dan waktu pirolisis adalah $325^{\circ} \mathrm{C}$ dan waktu 2 jam. 


\section{DAFTAR PUSTAKA}

[1] Jambeck Jenna R et al., "Plastic waste inputs from land into the ocean," Science (80-. )., 2015.

[2] P. Purwaningrum, "UPAYA MENGURANGI TIMBULAN SAMPAH PLASTIK DI LINGKUNGAN,” Indones. J. URBAN Environ. Technol., 2016.

[3] U. B. Surono and I. Ismanto, "Pengolahan Sampah Plastik Jenis PP, PET dan PE Menjadi Bahan Bakar Minyak dan Karakteristiknya," J. Mek. Dan Sist. Termal, vol. 1, no. 1, pp. 32-37, 2016.

[4] M. Syamsiro et al., "Fuel oil production from municipal plastic wastes in sequential pyrolysis and catalytic reforming reactors," in Energy Procedia, 2014.

[5] N. Hidayah and Syafrudin, "A Review on Landfill Management in the Utilization of Plastic Waste as an Alternative Fuel," in E3S Web of Conferences, 2018.

[6] E. Kurniawan and Nasrun, "Karakterisasi Bahan Bakar dari Sampah Plastik Jenis High Density Polyethelene (HDPE) Dan Low Density Polyethelene (LDPE)," J. Teknol. Kim. Unimal, 2017.

[7] R. Prihandana, R. Hendroko, and M. Nuramin, Menghasilkan Biodiesel Murah, Mengatasi Polusi \& Kelangkaan BBM. Jakarta: AgroMedia Pustaka, 2006.

[8] T. Landi and A. Arijanto, "PERANCANGAN DAN UJI ALAT PENGOLAH SAMPAH PLASTIK JENIS LDPE (LOW DENSITY POLYETHYLENE) MENJADI BAHAN BAKAR ALTERNATIF," J. Tek. Mesin Undip, 2017.

[9] J. M. Marchetti and A. F. Errazu, "Comparison of different heterogeneous catalysts and different alcohols for the esterification reaction of oleic acid," Fuel, 2008 .

[10] J. Wahyudi, H. T. Prayitno, and A. D. Astuti, "PEMANFAATAN LIMBAH PLASTIK SEBAGAI BAHAN BAKU PEMBUATAN BAHAN BAKAR ALTERNATIF," J. Litbang Media Inf. Penelitian, Pengemb. dan IPTEK, 2018.

[11] G. L. Sari, "KAJIAN POTENSI PEMANFAATAN SAMPAH PLASTIK MENJADI BAHAN BAKAR CAIR,” Al-Ard J. Tek. Lingkung., 2018. 